\title{
Protected values: No omission bias and no framing effects
}

\author{
CARMEN TANNER \\ University of Zurich, Zurich, Switzerland \\ and \\ DOUGLAS L. MEDIN \\ Northwestern University, Evanston, Illinois
}

\begin{abstract}
Previous studies have suggested that people holding protected values (PVs) show a bias against harmful acts, as opposed to harmful omissions (omission bias). In the present study, we (1) investigated the relationship between PVs and acts versus omissions in risky choices, using a paradigm in which act and omission biases were presented in a symmetrical manner, and (2) examined whether people holding PVs respond differently to framing manipulations. Participants were given environmental scenarios and were asked to make choices between actions and omissions. Both the framing of the outcomes (positive vs. negative) and the outcome certainty (risky vs. certain) were manipulated. In contrast to previous studies, PVs were linked to preferences for acts, rather than for omissions. PVs were more likely to be associated with moral obligations to act than with moral prohibitions against action. Strikingly, people with strong PVs were immune to framing; participants with few PVs showed robust framing effects.
\end{abstract}

People often express moral opinions concerning environmental problems, such as global warming, pollution, or endangered species. Research on judgment and decision making conducted by Ritov, Baron, and associates (e.g., Baron \& Ritov, 1994; Baron \& Spranca, 1997; Ritov \& Baron, 1990, 1999) has shown that people sometimes have protected values (PVs), which are absolute values that people protect from tradeoffs (Fiske \& Tetlock, 1997). Furthermore, PVs are believed to arise from deontological principles, rather than from consequentialist assessments of gains and losses. Importantly, PVs have been linked to omission bias: a tendency to favor the omission over the act when a choice must be made between a harmful act (e.g., killing somebody) and an otherwise equivalent harmful omission (e.g., letting somebody die). In such cases, people often judge harmful acts to be morally worse than harmful omissions. Consider this paraphrase of a typical example from Ritov and Baron (1990): "An epidemic will cause 1,000 children to die, and a vaccine is available that would prevent these deaths but would cause 100 children to die. Would you use the vaccine?" Ritov and Baron found that often people rejected this tradeoff on the grounds that they would not want to cause the death of any children. A few participants said that they would not vaccinate if the procedure caused the death of even a single child. People who held PVs for human life (independently assessed) showed a greater reluctance to trade off (larger

This research was supported by Swiss National Science Foundation Grant 8210-61241 to the first author and NSF Grant SES-9910156 to the second author. Address correspondence to C. Tanner, University of Zurich, Social and Business Psychology, Rämistrasse 62, 8001 Zurich, Switzerland (e-mail: ctanner@ psychologie.unizh.ch). omission bias) than did people without a PV. Omission bias with people holding PVs has been shown in numerous studies and in a variety of environmental and social contexts (see Markman \& Medin, 2002, for a review). Overall, the dominant interpretation is that PVs are deontological prohibitions against action that shape a tendency toward omissions.

In sharp contrast, there is related research on environmental behavior that suggests that PVs are not only about prohibitions but can also be associated with commitment to action. Studies in which the role of moral norms in environmental behaviors has been investigated have consistently found that people endorsing moral values are more inclined to express such values through active behaviors, rather than through inaction (e.g., Black, Stern, \& Elworth, 1985; Cialdini, Reno, \& Kallgren, 1990; Hopper \& Nielsen, 1991; Stern, Dietz, \& Kalof, 1993). People with such value orientations are more willing to pursue environmental protection in the face of negative economic or social outcomes (Axelrod, 1994). They may be driven (at least partially) by nonconsequentialist (deontological) principles (their rationale for action is that it is "the right thing to do"). Rather than moral prohibitions against action, this research indicates a role for "oughts" in terms of moral obligation to act.

This research on environmental values and moral obligations has received little attention from the judgment and decision making (JDM) literature. JDM research has suggested that PVs are closely linked to omission bias, but this relation may have been overgeneralized. The emphasis on omission bias may also have contributed to action effects' being largely ignored in decision making research (see also Patt \& Zeckhauser, 2000). Action effects 
are interesting because they conflict with omission bias and other well-known decision rules, such as loss aversion and status quo bias, both of which favor inaction. The present study focuses on the relationship between PVs and action tendencies in decision making.

Comparing the literature on environmental behavior and action effects based on moral obligation, on the one hand, and the literature on omission bias and inaction effects on the other, raises a central question: Which circumstances produce one pattern of results versus the other? One candidate factor is whether acts versus omissions are about negative or positive outcomes. Prohibitions against action may be salient when the act can be seen as causing harm. In contrast, obligation to act may be more salient when the act can be seen as promoting something good. In line with this, Patt and Zeckhauser (2000) recently proposed that action bias is complementary to omission bias, the latter focusing on losses and the former on gains. This suggests that act versus omission bias can be manipulated by situational cues, such as positive versus negative framing of options. In our study, we explore how PVs are related to framing.

We believe that omission bias and tradeoff reluctance may not be solely tied to moral prohibitions. In an unpublished study that we (along with Chun-Hui Miao) conducted using the paradigm employed by Ritov, Baron, and associates (Baron \& Ritov, 1994; Baron \& Spranca, 1997; Ritov \& Baron, 1990, 1999), we replicated the finding that PVs are associated with greater omission bias, but the justifications provided by the participants suggested that responding typically was not guided by moral prohibitions. The most common reasons given for rejecting tradeoffs involved either differentiating the components of the tradeoffs or a moral obligation to act. For example, in a scenario in which the participants were asked to trade 100 square miles of old growth forest that were part of a national park to save 1,000 square miles of old growth forest from being logged, the participants often declined on the grounds that the park might have historical and sentimental value and/or cited an obligation to act to protect national parks from logging interests. Justifications for declining tradeoffs on grounds of moral prohibitions were rarely provided.

Furthermore, the typical paradigm in which omission bias has been found has something of an asymmetrical flavor. In most studies in which omission bias has been examined, this tendency has been measured by asking participants for a threshold amount of harm from action (Ritov \& Baron, 1999). Participants are asked to make a tradeoff, where anything less than a complete tradeoff (giving up 999 square miles of forest to save 1,000 square miles of forest) represents an omission bias. Technically, participants can show a commission bias (by being willing to give up more than 1,000 square miles of forest to save 1,000 square miles of forest), but the pragmatics of the situation weigh heavily against this. Our study offers omission and commission choices that are more nearly symmetrical. For this purpose, we modified Tversky and Kahneman's (1981) risky choice framing paradigm, in which an outbreak of disease threatens to kill 600 people and one option will save 200 people for sure and the other has a one-third chance of saving all 600 and a twothirds chance of saving no one. In the alternative framing, the same outcomes are described in terms of lives lost. People are more risk seeking in the negative frame and more risk averse in the positive frame. Our modification was to make one option an active choice and the other a default consequence. For example, participants might be told that if they adopt Plan A, 200 people will be saved for sure, but if they do nothing, there is a onethird chance that all 600 will be saved and a two-thirds chance that no one will be saved. Both the framing of the environmental outcome focus (positive vs. negative outcomes) and the certainty of the outcomes (risky vs. certain) associated with the options were manipulated.

To our knowledge, no previous study has examined PVs and their relation to framing. The framing paradigm assesses the relationship between PVs and acts/omissions in a more symmetrical context (responses indicating avoidance of harmful acts and those indicating a duty to act were equally possible). In our study, people were given four hypothetical environmental scenarios. Previous work on omission bias has also used environmental scenarios, so there is no reason to expect that environmental scenarios per se will affect performance.

The experiment addressed three related questions. (1) How strongly are PVs related to acts versus omissions and moral prohibitions versus moral obligations? (2) Is the prevalence of obligation versus prohibition and act versus omission bias sensitive to negative/positive framing? (3) Do people holding PVs respond differently to framing manipulations?

On the basis of the environmental behavior literature, we would expect choices favoring acts over omissions. From the work of Ritov, Baron, and collaborators, one would predict that PVs should lead to omissions, rather than to acts. Furthermore, if a loss framing makes people with PVs more likely to follow prohibitions against action, one would expect more omission bias under loss framing.

The third question is a result of the claim that PVs are deontological rules. Because PVs are based on deontological rules, people are expected to attend more to the activity per se than to the magnitude of the consequences. People holding strong PVs may follow rules that apply to the act. Given that they try to be consistent with their principles, people holding PVs should resist framing manipulations. Recently, Wang (1996) suggested that people with strong preferences may become immune or insensitive to the framing manipulations. PVs may be a promising candidate for such strong preferences.

\section{METHOD}

\section{Participants}

Seventy-eight Northwestern University undergraduates (41 women and 37 men) participated in the study for course credit. The participants ranged in age from 17 to 22 years (mean $=19$ years). Gender did not affect the measures. 


\section{Materials and Procedure}

The experiment involved four hypothetical scenarios related to environmental issues (polychlorinated biphenyls, carbon dioxide emission, genetically engineered crops, and drinking water contamination; see Appendix A for a full description). Each scenario contained a choice between an act and an omission (e.g., vaccinating vs. not vaccinating children suffering from having drunk contaminated water). The choice problem was framed either positively or negatively. In the positive condition, the outcomes were framed in terms of human or animal lives saved or harmful emissions reduced. In the negative condition, the outcomes were described as lives lost or undesirable emissions released. In addition, the likelihood of the outcomes associated with the act was either certain (whereas the omission outcome was risky) or risky (whereas the omission outcome was certain), but of equal expected value. Four versions of the questionnaire with different orders of scenarios were created, each given to approximately $25 \%$ of the participants.

The participants were randomly assigned to one of four experimental groups, corresponding to the four possible combinations from the two frames (positive or negative) and the two kinds of outcomes associated with an act or an omission (certain or risky). The participants were asked to play the role of a person empowered to make a decision between two alternatives and to justify their choices in one or two sentences. After responding to the scenarios, the participants were asked to respond to a set of questions designed to measure the PVs. The items were adapted after Baron and Spranca (1997) and Baron (1999; see Appendix B). Other items, not relevant for the present article, were designed to measure moral values, and we will report only the results related to PVs.

\section{RESULTS}

Scenario order did not affect the results. ${ }^{1}$ Table 1 shows the proportion of act preferences and the proportion of participants who endorsed PVs ("people should do this no matter how small the benefits"), as well as the correlation between PVs and act preferences for each scenario. Across scenarios, the percentage of participants endorsing PVs ranged from $28 \%$ to $73 \%$. In three of four scenarios, a significant positive correlation was observed, indicating that the participants with PVs tended to prefer acts over omissions more often than did the participants without PVs. We also counted the participants' expressions of PVs across all scenarios and correlated this with the number of act choices across the scenarios. This correlation was $r=.24(p<.05)$.

Next, a repeated measures analy sis of variance (ANOVA; frame $\times$ act certainty $\times \mathrm{PV} \times$ scenario) was performed, with scenario as a within-subjects variable and frame, act certainty, and PV as between-subjects variables. The participants' expressions of PVs were counted across the sce-

Table 1

Proportions of Act Preferences as a Function of the Presence or Absence of Protected Values (PVs), Along With Overall Proportions of PVs and Correlations Between PV and Act Preference

\begin{tabular}{lcccc}
\hline \multirow{2}{*}{\multicolumn{1}{c}{ Scenarios }} & \multicolumn{2}{c}{ Act } & \multirow{2}{*}{$\begin{array}{c}\text { Proportion } \\
\text { of PV }\end{array}$} \\
\cline { 2 - 5 } & PV & No PV & $r$ \\
\hline Polychlorinated biphenyls & .77 & .52 & .73 & $.24^{*}$ \\
Carbon dioxide emission & .62 & .34 & .47 & $.28^{*}$ \\
Genetically engineered crops & .46 & .41 & .28 & .05 \\
Drinking water contamination & .74 & .50 & .64 & $.26^{*}$ \\
\hline
\end{tabular}

$* p<.05$. narios, and two groups, people with low versus high numbers of PVs, were created (low PV $=0$ or 1 endorsement of PVs across scenarios, high PV $=3$ or 4 endorsements). This analysis excluded data from participants with an intermediate number (2) of PVs; 21 participants had a low number of PVs, and 31 had a high number. Choice of act versus omission was the dependent variable.

Tests of within-subjects factors yielded only two significant effects. The reliable main effect for scenario confirmed the descriptive analysis, mentioned above, that the proportion of act preferences varied across the four scenarios $\left[F(3,126)=5.06, M S_{\mathrm{e}}=0.76, p<.01\right]$. In addition, the scenario $\times$ act certainty interaction was also reliable $\left[F(1,126)=3.13, M S_{\mathrm{e}}=0.4, p<.05\right]$, indicating that the role of certain versus risky outcomes associated with the options varied across the scenarios.

Tests of between-subjects factors yielded three significant effects. The main effect of PV $[F(1,42)=5.65$, $\left.M S_{\mathrm{e}}=1.87, p<.05\right]$ reflected the fact that high-PV participants were generally more likely to prefer acts $(M=$ $66 \%$ ) than were people with low PVs (45\%). In addition, the frame $\times$ act certainty interaction was reliable $\left[F(1,42)=9.62, M S_{\mathrm{e}}=3.19, p<.01\right]$. This interaction was qualified by a three-way interaction of frame, act certainty, and PVs $\left[F(1,42)=5.42, M S_{\mathrm{e}}=1.80, p<\right.$ $.05] .{ }^{2}$ This three-way interaction is consistent with the observation that the interaction of framing with act certainty is driven by the participants with few PVs. ${ }^{3}$

Figure 1 shows this interaction. Note that the data from the participants with few PVs replicate those of Tversky and Kahneman (1981). With a positive frame, there was a strong preference for the riskless option. Acts were preferred when associated with certain outcomes (69\%), but not when associated with risky outcomes (13\%). The difference between act preferences for the conditions in which certain versus risky outcomes were associated with the act was significant $\left[F(1,9)=36.88, M S_{\mathrm{e}}=2.53, p<\right.$ $.001]$. This pattern was reversed under negative framing. Acts were preferred for risky outcomes (69\%), but not for certain outcomes $(31 \%)$. The difference between act preferences under certain versus risky outcomes associated with the act was marginally significant $[F(1,12)=$ $\left.3.29, M S_{\mathrm{e}}=1.50, p<.10\right]$. Overall, low-PV participants showed little preference for acts per se $(41 \%$ with the positive frame and $50 \%$ with the negative frame).

The high-PV participants displayed a strikingly different picture. First, they showed no framing effect. In the positive and negative frames, acts were preferred regardless of whether the act had certain or risky outcomes $(80 \%$ vs. $56 \%$ and $69 \%$ vs. $58 \%$, respectively). There is a clear preference for acts for both the positive $(68 \%)$ and the negative $(64 \%)$ frames. Far from being linked to prohibitions, high numbers of PVs were associated with a clear preference for actions. Finally, a modest but not significant preference was shown for certain over risky choices $[F(1,11)=1.87$, n.s., and $F(1,15)=0.57$, n.s., under positive and negative frames, respectively].

ANOVAs were also conducted for each scenario separately. Closer inspection of the results revealed similar 


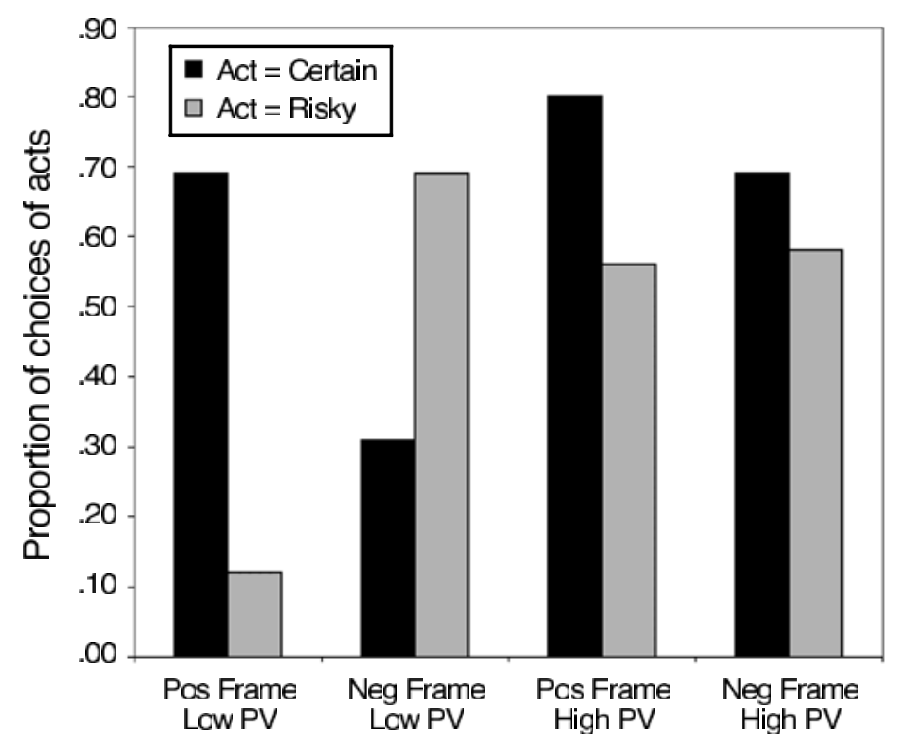

Figure 1. Proportions of choices of acts as a function of framing (positive or negative), certainty of act outcomes, and endorsement of protected values (PVs).

patterns for all the scenarios. As can be seen in Table 2, in all cases, people with PVs were insensitive to framing, whereas people with low PVs were not. This tendency was significant only in the polychlorinated biphenyls scenario $\left[F(1,42)=4.28, M S_{\mathrm{e}}=0.93, p<.05\right]$ and was marginally significant in the genetically engineered crops $\left[F(1,42)=3.18, M S_{\mathrm{e}}=0.79, p<.08\right]$ and drinking water contamination $\left[F(1,42)=1.86, M S_{\mathrm{e}}=0.33, p<\right.$ .12] scenarios.

Finally, we examined justifications for choices. Two raters, blind to each participant's experimental condition and the purpose of the study, independently grouped the justifications into one of six categories: (1) risk evaluation (present if the response was based on examining the probabilities and chances involved with the options; e.g., "Alternative B is better, because it is the only sure thing"); (2) moral obligation to act (statements indicating that people have a responsibility to prevent harm or to help; e.g., "you have to do everything you can to help"); (3) moral prohibition against harmful acts (statements indicating that causing or allowing harm by doing something or doing nothing would be unacceptable; e.g., "I would not want to be held responsible for the damage"); (4) prioritizing saving environment/lives (response indicating that saving the environment/humans is most important [but without explicitly mentioning moral thoughts]; e.g., "saving the environment is more important than saving a little money"); (5) concern for other values/strategy evaluation (citing other values [such as costs] as more important or statements reflecting the intervention's effectiveness or benefits; e.g., "this will cost my company less"); and (6) others.

Overall, the interrater reliability, Cohen's kappa, was $k=.79$. Disagreements were resolved through discussion. The results are summarized in Table 3.
For our purposes, Categories 2 and 3 are crucial. Overall, in $37 \%$ of all cases in which an act was preferred over an omission, people gave answers that reflected moral obligations to act. In some cases, the act preference appeared to be motivated by the thought that doing nothing would be morally unacceptable $(8 \%)$. Regarding preferences for omissions, we found in $13 \%$ of the cases that people mentioned moral prohibitions. Furthermore, highPV respondents gave significantly more moral obligation statements than did low-PV respondents $[t(50)=$ $2.33, p<.05]$. Moral prohibition statements were not given more often by high- than by low-PV respondents $[t(50)=0.15$, n.s.]. Overall, these results confirm that PVs are associated with a greater endorsement of moral obligations than of moral prohibitions.

\section{Table 2}

Proportions of Choices of Acts as a Function of Framing, Certainty of Action Outcomes, and Protected Values (PVs) for Each Scenario

\begin{tabular}{|c|c|c|c|c|}
\hline \multirow[b]{2}{*}{$\begin{array}{c}\text { Outcome } \\
\text { of Act }\end{array}$} & \multicolumn{2}{|c|}{ Low PVs } & \multicolumn{2}{|c|}{ High PVs } \\
\hline & $\begin{array}{c}\text { Positive } \\
\text { Frame }\end{array}$ & $\begin{array}{c}\text { Negative } \\
\text { Frame }\end{array}$ & $\begin{array}{c}\text { Positive } \\
\text { Frame }\end{array}$ & $\begin{array}{c}\text { Negative } \\
\text { Frame } \\
\end{array}$ \\
\hline \multicolumn{5}{|c|}{ Polychlorinated Biphenyls } \\
\hline Certain & 1.00 & .25 & .80 & .63 \\
\hline Risky & .25 & .75 & .75 & .67 \\
\hline \multicolumn{5}{|c|}{ Carbon Dioxide Emission } \\
\hline Certain & .75 & .25 & 1.00 & .75 \\
\hline Risky & .00 & .25 & .45 & .44 \\
\hline \multicolumn{5}{|c|}{ Genetically Engineered Crops } \\
\hline Certain & .55 & .25 & .60 & .55 \\
\hline Risky & .00 & .75 & .50 & .33 \\
\hline \multicolumn{5}{|c|}{ Drinking Water Contamination } \\
\hline Certain & .50 & .50 & .80 & .86 \\
\hline Risky & .25 & 1.00 & .75 & .89 \\
\hline
\end{tabular}


Table 3

Proportion of Justifications for Choosing Action or Omission

\begin{tabular}{|c|c|c|c|c|c|c|}
\hline Choice & $\begin{array}{c}\text { Risk } \\
\text { Evaluation }\end{array}$ & $\begin{array}{c}\text { Moral } \\
\text { Obligation }\end{array}$ & $\begin{array}{c}\text { Moral } \\
\text { Prohibition }\end{array}$ & $\begin{array}{c}\text { Prioritizing } \\
\text { Environment/ } \\
\text { Human Lives }\end{array}$ & $\begin{array}{c}\text { Other Values/ } \\
\text { Strategy } \\
\text { Evaluation }\end{array}$ & Others \\
\hline Action & .33 & .38 & .08 & .08 & .11 & .02 \\
\hline Omission & .44 & .02 & .13 & .07 & .32 & .02 \\
\hline
\end{tabular}

\section{DISCUSSION}

We found that people with PVs were more likely to prefer acts than omissions. In addition, PVs were more closely associated with a sense of obligation to act, rather than with prohibitions against action (participant justifications also support this claim). This result is in sharp contrast with those of previous studies showing that PVs are associated with an omission bias. Unlike prior work, our paradigm presented acts and omissions in a more symmetrical problem context, and that may have been the key factor in producing the differing outcomes. We think our framing paradigm is a useful methodological innovation for studying PVs.

Actions were preferred over omissions in both positive and negative frames. This is inconsistent with the hypothesis that loss framing will trigger an omission bias. Patt and Zeckhauser (2000) have suggested that action tendencies can sometimes be strong enough to overcome even loss aversion and omission bias. In line with this, our findings also suggest that action tendencies are not limited to situations involving gains. An alternative explanation, however, may be that people with PVs have frame preferences and generally tend to reformulate the options in positive terms (see Reyna \& Brainerd, 1991, for an elaboration of this general idea). This would suggest that action tendencies concern outcomes that are "perceived" as positive, with perception not necessarily corresponding to the objective framing. The connection between action/omission biases and subjective valuation is a matter for future research.

The second striking finding was that the participants with strong PVs did not show framing effects. The participants with few PVs showed robust framing effects, in line with prospect theory (Kahneman \& Tversky, 1984) and prior research. This difference in susceptibility to framing was shown, at least directionally. It seems clear that situational factors cannot fully explain the present findings, such as the observation that PVs showed robust act preferences in both frames. This leads us to assume that individual differences in information processing are at work. We cannot distinguish (so far) between the scenario-specific effects of having a PV and the idea that people with lots of PVs are different from people with few PVs. Perhaps people holding strong PVs try to satisfy their values, which may work like well-established beliefs or rules that are not malleable. Again, this could be a stable individual difference or a strategy triggered by a scenariospecific PV.
One reviewer of this article raised the question of whether people with high PVs are inclined to reason deontologically and to be immune to framing effects in all domains or whether there are situational limitations. Although we varied the problem descriptions broadly, each concerned environmental decision making, and therefore, additional research that includes other contexts is needed to examine the scope of the findings for the interaction of individual and contextual factors.

A related issue is that in our study, the participants were asked to assume the role of someone with the authority to make decisions. A moral obligation to act is likely a function of social roles (see also Haidt \& Baron, 1996), and the link between PVs and acts versus omissions may vary with social roles. At a minimum, however, the present study shows that research on framing may benefit from taking account of PVs as a moderating factor. Overall, the main results of this study can be summarized as follows: (1) PVs are not inevitably linked to prohibitions against action, and (2) PVs may be associated with the absence of framing effects.

\section{REFERENCES}

AXELROD, L. J. (1994). Balancing personal needs with environmental preservation: Identifying the values that guide decisions in ecological dilemmas. Journal of Social Issues, 50, 85-104.

BARON, J. (1999). Consumer attitudes about personal and political action. Journal of Consumer Psychology, 8, 261-275.

BARON, J., \& Ritov, I. (1994). Reference points and omission bias. Organizational Behavior \& Human Decision Processes, 59, 475-498.

BARON, J., \& SPRANCA, M. (1997). Protected values. Organizational Behavior \& Human Decision Processes, 70, 1-16.

Black, J. S., Stern, P. C., \& ElWorth, J. T. (1985). Personal and contextual influences on household energy adaptations. Journal of Applied Psychology, 70, 3-21.

Cialdini, R. B., Reno, R. R., \& Kallgren, C. A. (1990). A focus theory of normative conduct: Recycling the concept of norms to reduce littering in public places. Journal of Personality \& Social Psychology, 58, 1015-1026.

Fiske, A. P., \& TeTlock, P. E. (1997). Taboo trade-offs: Reactions to transactions that transgress spheres of justice. Political Psychology, 18, 255-297.

HAIDT, J., \& BARON, J. (1996). Social roles and the moral judgement of acts and omissions. European Journal of Social Psychology, 26, 201218.

HopPer, J. R., \& NiElSEN, J. M. (1991). Recycling as altruistic behavior: Normative and behavioral strategies to expand participation in a community recycling program. Environment \& Behavior, 23, 195-220.

Kahneman, D., \& TVERSKy, A. (1984). Choice, values, and frames. American Psychologist, 39, 341-350.

Markman, A. B., \& Medin, D. L. (2002). Decision making. In H. Pashler \& D. L. Medin (Eds.), Stevens' Handbook of experimental psychology: Vol. 2. Memory and cognitive processes (3rd ed., pp. 413466). New York: Wiley. 
PATT, A., \& ZECKHAUSER, R. (2000). Action bias and environmental decisions. Journal of Risk \& Uncertainty, 21, 45-72.

REYNA, V. F., \& BRAINERD, C. J. (1991). Fuzzy-trace theory and framing effects in choice: Gist extraction, truncation, and conversion. Journal of Behavioral Decision Making, 4, 249-262.

RITOV, I., \& BARON, J. (1990). Reluctance to vaccinate: Omission bias and ambiguity. Journal of Behavioral Decision Making, 3, 263-277.

Ritov, I., \& BARON, J. (1999). Protected values and omission bias. Organizational Behavior \& Human Decision Processes, 79, 79-94.

STERn, P. C., Dietz, T., \& KALOF, L. (1993). Value orientations, gender, and environmental concern. Environment \& Behavior, 25, $322-$ 348 .

TVERSKy, A., \& Kahneman, D. (1981). The framing of decisions and the psychology of choice. Science, 211, 453-458.

WANG, X. T. (1996). Framing effects: Dynamics and task domains. Organizational Behavior \& Human Decision Processes, 68, 145-157.

\section{NOTES}

1. One of the reviewers suggested that explicitly mentioning "environmental activist" in the drinking water contamination scenario could have created a demand characteristic to focus on actions, rather than on omissions. Of course, one would need to have an account of why this priming would affect people with PVs and not those without them. Nonetheless, we addressed this priming issue with additional analyses looking at order effects. In one version, the activist scenario was the first one provided; in another, it was the last one. The proportion of the act preferences of the other scenarios was a bit lower in the former case $(45 \%)$ than in the latter one $(53 \%)$. In the two other sequences, the activist scenario was neither first nor last, and we found no difference in act preference for scenarios that preceded versus followed the activist scenario. Overall, there is no evidence that the activist scenario biased the participants toward acts of commission.

2. Excluding data from the participants with an intermediate number of PVs potentially entails a loss of information. In a supplementary analysis, we regressed number of protected values, framing, and act certainty and their interactions onto number of choices of the acts for the scenarios. This regression was statistically reliable $[F(7,70)=3.61$, $\left.M S_{\mathrm{e}}=4.28, p<.01\right]$ and accounted for $27 \%$ of the variance. By this analysis, all three main effects, the two-way interactions, and the threeway interaction were statistically significant $(p<.05)$.

3. Previous research also suggests that PV coincides with universal morality (Baron \& Spranca, 1997). Universal moral values (UMVs) reflect a commitment to particular rules that everybody should comply with, independently of what the individual may think ("people have a moral obligation to undertake such an action even if they do not want to undertake it"). The correlation of number of PVs and UMVs across all scenarios was $r=.44(p<.01)$. A corresponding analysis with UMVs substituting for PVs revealed essentially the same pattern. That is, people with high UMVs were more likely to prefer the act option. Similarly, they were also insensitive to framing effects, whereas people with low UMVs showed the usual framing effects.

\section{APPENDIX A \\ Choice Scenarios Used in the Study}

\section{Drinking Water Contamination}

Imagine a refinery that processes petroleum products. An investigation found that due to tank leaks, both soil and drinking water became contaminated. Due to this contamination 720 children from the adjacent village have a fatal disease. There is agreement among experts that children will not suffer health problems, provided they have a strong immune system. Otherwise, it is likely that children will have serious health problems. A vaccine against this disease has been developed and tested. However, the vaccine sometimes can cause side effects that can be fatal too. You are an environmental activist with much influence on the local hospital and you have to decide if you want to lobby for the vaccination or not. Which of the options would you favor? Assume that the estimates are as follows.

1. Negatively framed, act with certain outcomes:

(a) If the vaccination is adopted, the health of 480 children will be damaged for sure.

(b) If no vaccination is adopted, there is a one-third probability that the health of none of the 720 children will be damaged, and a two-thirds probability that the health of all of them will be damaged.

2. Negatively framed, act with risky outcomes:

(a) If the vaccination is adopted, there is a one-third probability that the health of none of the 720 children will be damaged, and a two-thirds probability that the health of all of them will be damaged.

(b) If no vaccination is adopted, the health of 480 children will be damaged for sure.

3. Positively framed, act option with certain outcomes:

(a) If the vaccination is adopted, the health of 240 children will be saved for sure.

(b) If no vaccination is adopted, there is a one-third probability that the health of all of the 720 children will be saved, and a two-thirds probability that the health of none of them will be saved.

4. Positively framed, act option with risky outcomes:

(a) If the vaccination is adopted, there is a one-third probability that the health of all of the 720 children will be saved, and a two-thirds probability that the health of none of them will be saved.

(b) If no vaccination is adopted, the health of 240 children will be saved for sure.

\section{Polychlorinated Biphenyls in the Environment}

You are the head of a big electronic machine plant in a village. Due to improper disposal of hazardous waste into the environment through waste incinerators and landfills, you are concerned about the exposure of 6,000 inhabitants to polychlorinated biphenyls (PCBs). Experts agree that accumulation of PCBs in the human body can cause a variety of health problems, such as skin, liver, and gastrointestinal problems. You have to choose 


\section{APPENDIX A (Continued)}

between two strategies for reducing the problem and protecting human health. You can make the plant implement a cleanup program to remove PCB from products which have been previously disposed of. You know that, if you don't implement this program, then the municipality plans to implement a program that should insure proper removal of PCB from future electrical equipment and products. Which one would you favor? Assume that the characteristics of both strategies are as follows.

1. Negatively framed, act with certain outcomes:

(a) You implement the cleanup program of the plant. With this, the health of 4,000 inhabitants will be damaged.

(b) You do nothing and wait for the municipality program. With this, there is a one-third probability that the health of none of the inhabitants will be damaged, and a two-thirds probability that the health of all of them will be damaged.

[The other conditions were performed in analogy to the description above.]

\section{Carbon Dioxide Emissions}

Imagine a plant which discharges 120 tons of carbon dioxide $\left(\mathrm{CO}_{2}\right)$ each year as a result of product processing. You are the director of this plant and you know that $\mathrm{CO}_{2}$ is the most relevant greenhouse gas. You have to decide whether or not to install filters that help to reduce $\mathrm{CO}_{2}$ emissions. However, there is also a certain chance that the municipality will plant trees around the plant. Trees absorb $\mathrm{CO}_{2}$ and other toxins which enter the environment and are therefore important "carbon sinks." Only one of these options can be implemented. Which of the options would you favor? Assume that the exact scientific estimates are as follows.

1. Negatively framed, act with certain outcomes:

(a) If you install the filters, 80 tons of $\mathrm{CO}_{2}$ will be released in the atmosphere for sure.

(b) If you do not install the filters and the municipality's plan is implemented, there is a one-third probability that none of the plant's $\mathrm{CO}_{2}$ emissions will be left in the environment, and a two-thirds probability that all $\mathrm{CO}_{2}$ emissions will be left.

[The other conditions were performed in analogy to the description above.]

\section{Genetically Engineered Crops}

Some years ago, in the village where you live, the farmers adopted eight new genetically engineered crops to save costs. According to the experts, there are concerns that the population of 9 species of beneficial insects have already decreased dramatically and could even become extinct. One of the reasons may be that the insects eat pollen from genetically modified corn. The local government is considering enacting a law that should limit the use of genetically engineered crops from eight to two. As an influential member of the government, you can lobby for this law or not. Assume that the exact scientific estimates of the consequences are as follows.

1. Negatively framed, act with certain outcomes:

(a) If the law is enacted, 6 insect species will become extinct.

(b) If the law is not enacted, there is a one-third probability that none of the 9 insect species will become extinct, and a two-thirds probability that all of them will become extinct due to other reasons.

[The other conditions were performed in analogy to the description above.]

\section{APPENDIX B}

\section{Measure of Protected Values}

How do you think about [a vaccination to protect children's health; implementing a cleanup program to save the health of the inhabitants; installing filters to reduce $\mathrm{CO}_{2}$; enacting a law to safeguard insect species]?

(a) People should only undertake this action if it leads to some benefits that are great enough.

(b) People should do this no matter how small the benefits. [= protected value].

(c) Not undertaking the action is acceptable if it saves people enough money.

\section{Measure of Morality}

How do you think about the morality of undertaking an action like this?

(a) People have no moral obligation to undertake such an action.

(b) People have a moral obligation to undertake such an action even if they do not want to undertake it. [= universal moral]

(c) People have a moral obligation to undertake such an action, but it is each person's own business. [= personal moral] 